\title{
Gömülü Yirmi Yaş Dişi Çekimi Endikasyonu Konulmuş Hastalarda Operasyonun Hemen ya da Gecikmeli Yapılmasının Dental Anksiyete ve Dental Korku Üzerine Etkisinin Değerlendirilmesi
}

\author{
Evaluation of the effect of immediate or delayed operation on dental anxiety and dental fear in \\ patients with impacted wisdom teeth

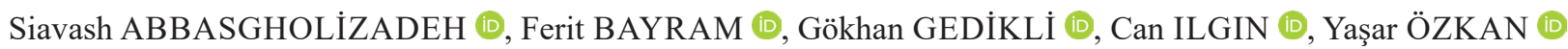

Öz

Amaç: Gömülü yirmi yaş dişi çekimi endikasyonu konulmuş hastalarda operasyonun hemen ya da gecikmeli yapılmasının dental anksiyete ve dental korku düzeyine etkisinin değerlendirilmesidir.

Gereç ve Yöntem: Gömülü yirmi yaş dişi çekimi için başvuran ve çekim endikasyonu konulmuş hastalardan çalışmaya katılmayı kabul eden, daha önce gömülü yirmi yaş dişi çektirmemiş 40 gönüllü randomize olarak ikiye ayrıldı. Gönüllülerin yarısına endikasyon konulduğu gün, diğer yarısına randevu verilerek başka bir gün işlem yapıldı. Tüm gönüllülerin dental anksiyete, dental korku ve ağrı seviyelerini kaydetmek amaciyla Durumluluk Kayg1 Ölçeği, Dental Korku Skalası, Vizüal Analog Skala kullanıldı. Çalışma verileri değerlendirilirken Kruskal Wallis testi, Mann Whitney U testi, Friedman testi, Wilcoxon testi kullanıldı.

Bulgular: Fakülteye başvurduğu gün işlem yapılan gönüllülerin Spielberger Durumluluk Kayg1 Ölçeği değerleri randevu verilerek işlem yapılan gönüllülerden anlamlı olarak daha düşük bulunmuştur $(\mathrm{p}<0,05)$. Kadın gönüllülerin dental anksiyete değerleri erkeklere göre anlamlı olarak daha yüksek bulunmuştur $(\mathrm{p}<0,05)$. Dental anksiyetesi yüksek olan randevulu gruptaki gönüllülerin ağrı skorları da anlamlı olarak yüksek bulunmuştur $(\mathrm{p}<0,05)$.

Sonuçlar: Gömülü yirmi yaş dişi cerrahisi için randevu verilmesi hastaların anksiyete ve ağrı seviyelerini yükseltebildiğinden, operasyonların hemen yapılması hastaların yararına olacaktır.

Anahtar Kelimeler: dental anksiyete, dental korku, durumluluk kaygı ölçeği, dental korku skalası, vizüel analog skala

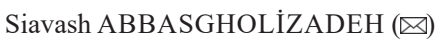

M.Ü Diş Hekimliği Fakültesi Ă̆ız, Diş ve Çene Cerrahisi Anabilim Dall, İstanbul, Türkiye

P.K : 34854

Tel: (+90)216.412.1621

Fax: (+90)216.421.0291

siyavus@gmail.com

Ferit BAYRAM, Gökhan GEDİKLİ, Can ILGIN, Yaşar ÖZKAN

Marmara Üniversitesi Diş Hekimliği Fakültesi Ăğz, Diş ve Çene Cerrahisi A.B.D, Istanbul, Türkiye

Submitted / Gönderilme: 22.11.2019

Accepted / Kabul: 27.12.2019

\section{Abstract}

Purpose: The purpose of this study is to evaluate the effect of immediate or delayed operation on dental anxiety and dental fear in patients with impacted wisdom teeth.

Material and methods: 40 patients who referred for wisdom tooth extraction and did not extract wisdom tooth before were divided into two groups randomly. 20 of the patients tooth extraction was made on the indication day. 20 of the patients were given an appointment for tooth extraction. Spielberger Stait-Trait dental anxiety scale, dental fear scale and visual analog scale was used to evaluate the dental anxiety and dental fear. Wallis test, Mann Whitney U test, Friedman test, Wilcoxon test were used for the evaluation of the study data.

Results: The patients who extracted their tooth on the day they applied to the faculty have shown significantly lower State Trate Anxiety Scale Score than the other group $(\mathrm{p}<0,05)$. Dental anxiety level of the female patients significantly higher than males $(p<0,05)$. Pain scores of patients with high dental anxiety were also significantly higher $(\mathrm{p}<0,05)$.

Conclusion: Giving an appointment for the wisdom tooth extraction can increase the anxiety and pain levels of patients, and it will be beneficial for patients to perform the operations immediately.

Keywords: dental anxiety, dental fear, state anxiety scale, dental fear scale, visual analog scale

\section{GíRiş}

Dental anksiyete diş tedavisi nedeniyle ortaya çıan korku ve endişe duygusudur (1). Anksiyete sendromu her yaşta, cinsiyette ve sosyal sınıfta görülebilmektedir. Ancak eğitim durumu, kişilik özellikleri, cinsiyet, yaş ve geçmiş dental tecrübeler hastaların anksiyete seviyelerini etkileyebilmektedir (2,3). Diş hekimi korkusu, birçok duygu kalıplarına bağlı olarak gelişen anksiyetenin bileşimidir. Bu korkunun altında ağrı korkusu, dişi kaybetme korkusu ve biri tarafından cezalandırma düşüncesi vardır. Diş kaybı vücut bütünlügüne verilen zarardır ve bu durum vücut bütünlüğü konusundaki diğer korkulardan kaynaklanabilir 
(4). Yirmi yaş dişlerinin cerrahi çekimi, genç yetişkinlerde ve ergenlerde diş hekimliği uygulamalarında yaygın olarak yapılmaktadır ve diğer diş hekimliği prosedürleri arasında genellikle yüksek endişe ve rahatsızlık ile ilişkilendirilir (5). Günümüzde korkunun gelişiminin iç etkenler ve dış etkenler olarak iki nedenden kaynaklı olduğu düşünülmektedir. Öğrenilen korku, etraftan duyulanlar sonucu oluşan klasik koşullanma ve daha önceki deneyimler diş etkenlerdir. İçsel etkenler ise kişinin hassasiyeti ile ilgilidir (6). Randevu almak, bekleme odasinda beklemek, dental ekipman ve işlemler dental korkunun gelişmesine neden olmaktadır. En fazla korku ise enjektörün görülmesi, enjeksiyon ve aeretöre karşı oluşmaktadır. Diş hekimliği korkusu ve kaygısı, randevu alma işlemi, tedavi öncesi bekleme odasında bekleme, dental tedavi sirasinda kullanılan aletler ve/veya yapılan işlemlere karşı gelişebilmektedir. (7-9).

Anksiyeteli hastalarda yirmi yaş dişi çekimi sadece hastalar için değil, aynı zamanda hekimler için de zor olabilir. $\mathrm{Bu}$ hastalar problemli, güvensiz, işbirliği yapmayan ve aşırı derecede şikâyetçi olabilirler. Cerrahi işlem yapılacağı zamana kadar geçen sürede hastaların genel anksiyete ve korkularının şiddeti de artabilir. Bu anket çalışmasının amacı, gömülü yirmi yaş dişi çekimi endikasyonu konulmuş hastalarda operasyonun hemen ya da gecikmeli yapılmasının dental anksiyete ve dental korku düzeyine etkisinin değerlendirilmesidir.

\section{GEREÇ VE YÖNTEM}

Bu çalışma Marmara Üniversitesi Diş Hekimliği Fakültesi Klinik Araştırmalar Etik Kurulu'nun 2017-130 sayılı etik onayı alınarak yapılmıştır.

$\mathrm{Bu}$ çalışma Marmara Üniversitesi Diş Hekimliği Fakültesi Ağız Diş ve Çene Cerrahisi Ana Bilim Dalı' na gömülü yirmi yaş dişi çekimi için başvuran ve çekim endikasyonu konulmuş hastalardan çalışmaya katılmayı kabul eden, daha önce gömülü yirmi yaş dişi çektirmemiş 40 gönüllüden oluşmaktadır.

Ciddi nörolojik, kardiyak, solunum sistemi rahatsızlığı bulunan, kontrolsüz dibeti olan, hematolojik hastalığ olan, baş-boyun radyoterapisi almış, bifosfanat türevi ilaç kullanan, hamile, alkol ya da ilaç bağımlılığı olan hastalar çalışmaya dahil edilmemiştir.

Sistemik olarak sağlıklı, 18 - 60 yaş arası çalışmaya katılmayı kabul eden, 40 gönüllü randomize olarak iki gruba ayrılmıştır.
Grup 1: Fakülteye başvurdukları gün endikasyon konulan ve aynı gün yirmi yaş cerrahisi yapılan gönüllüler

Grup 2: Fakülteye başvurdukları gün endikasyon konulan ve yirmi yaş cerrahisi için randevu verilen gönüllüler

Her iki gruptaki gönüllülere de işlem öncesi ve sonrası dental anksiyetelerini değerlendirmek amacıyla Spielberger Durumluk Kaygı Ölçeği Skalası (STAI-S), dental korkularını değerlendirmek amacıyla Dental Korku Skalası(DFS), ağrı seviyesi ve ağrı seviyesindeki değişimlerin değerlendirilmesinde Vizüel Analog Skalası (VAS) kullanılmıştır (Ek 2). Gönüllülerin yaş, cinsiyet, eğitim durumu, mesleği gibi demografik durumları da kaydedilerek dental anksiyete ve dental korku seviyeleriyle ilişkisinin olup olmadığı değerlendirilmiştir.

\section{Durumluluk Kaygı Ölçeğinin (STAI-S) Puanlaması}

$\mathrm{Bu}$ ölçekte yer alan sorulardan üç sorudan fazlasına yanıt verilmemesi durumunda, doldurulan form geçersiz sayıldı ve puanlanmadı. Doğrudan ve tersine dönmüş ifadelerin her biri için iki ayrı anahtar hazırlandı. Böylece bir anahtarla doğrudan ifadelerin, ikinci anahtarla tersine dönmüş ifadelerin toplam ağırlıkları hesaplandı. Doğrudan ifadeler için elde edilen toplam ağırlıklı puandan ters ifadelerin toplam ağırlıklı puanı çıkartıldı. Bu sayıya önceden tespit edilmiş ve değişmeyen bir değer olan "50" değeri eklendi. En son elde edilen değer bireyin anksiyete puanı olarak hesaplandi.

Anksiyete puanları hesaplanan gönüllüler Nakazato ve ark. hazırladığı sınıflamaya göre [22 puan ve altı çok düşük seviye (Seviye I), 23 puan ile 31 arası düşük seviye(Seviye II), 32 puan ile 40 puan arası normal seviye (Seviye III), 41 puan ile 49 puan arası yüksek seviye (Seviye IV), 50 puan ve üzeri çok yüksek seviye (Seviye V)] 5 gruba ayrıldı.

\section{Dental Korku Skalasının Puanlaması}

Dental korku skalasında yer alan sorulara verilen cevaplar için (neredeyse hiç cevabı "1" puan, çok az cevabı "2" puan, biraz cevabı " 3 " puan, çok cevabı " 4 "puan, çok fazla cevabı "5" puan) skorlama yapılarak gönüllülerin korku skalası puanları hesapland1. Korku skalası puanları hesaplanan gönüllüler Lopez-Jornet ve ark., hazırladığı sinıflamaya göre (0-33.33 arası puan hafif seviye, $33.34-66.66$ arası puan orta seviye, 66.67 - 100 arası puan şiddetli seviye) 3 gruba ayrild1. 


\section{Vizüel Analog Skala (Visual Analogue Scale: VAS) Puanlaması}

Hastaların ağrı seviyelerinin değerlendirilmesi amacıyla VAS skalası kullanıldı. Buna göre gönüllülerden işlem süresince, işlemden 1 gün sonra ve işlemden 1 hafta sonra olmak üzere hissettikleri ağrıyı 0 : hiç ağrı yok/ 10: dayanılmaz şiddette ağrıyı gösterecek şekilde, ağrılarını derecelendirmeleri istenildi.

\section{İstatistiksel Analiz}

Çalışmamızda elde edilen bulgular değerlendirilirken, istatistiksel analizler için Stata 15.1 (StataCorp LLC, Lakeway Drive, Texas) programı kullanılmıştır. Çalışma verileri değerlendirilirken tanımlayıcı istatistiksel metotlar frekans, yüzde, ortanca, çeyrekler arası dağılım aralığı (ÇADA), minimum ve maksimum değerler kullanılmıştır. İstatistiksel olarak anlamlılık $\mathrm{p}<0,05$ düzeyinde değerlendirilmiştir. Çalışma verileri değerlendirilirken gruplar arası değişkenlerin karşılaş̧ırmalarında Mann Whitney $U$ ve Kruskal Wallis testleri kullanılmıştır. Grupların kendi içinde zamana göre karşılaştırılmasında Friedman ve Wilcoxon testleri kullanılmıştır.

\section{BULGULAR}

Çalışmaya katılan 40 gönüllünün 22'(\%55) si kadın, 18'i (\%45) erkektir. Gönüllülerin yaş aralığ $18-42$ 'dir (ort: $24,875 \pm 5,689$ ). Gönüllülerin $\% 12,5$ 'i ilköğretim, \%52,5’i ortaöğretim, \%35'i ise yükseköğretim mezunudur.

\section{Durumluluk Kaygı Ölçeği (STAI-S) Sonuçları}

Gruplara göre STAI-S değerleri arasında istatistiksel olarak anlamlı fark olup olmadığına Mann-Whitney U testi ile bakılmıştır. Gruplar arasında anlamlı bir farklılık bulunmamıştır $(\mathrm{p}=0.0803)$.

Çalışma grupları, Durumluk Kaygı Ölçeği değerleri 5 sınıfa [(22 puan ve altı çok düşük seviye (Seviye I), 23 puan ile 31 arası düşük seviye(Seviye II), 32 puan ile 40 puan aras1 normal seviye (Seviye III), 41 puan ile 49 puan arası yüksek seviye (Seviye IV), 50 puan ve üzeri çok yüksek seviye (Seviye V)] ayrılarak karşılaştırıldığında ise gruplar arasında istatistiksel olarak anlamlı sonuçlar elde edilmiştir $(\mathrm{p}=0,0269)($ Tablo 1$)$
Tablo 1. Grupların STAI-S sınıflarının karşılaştırılması

\begin{tabular}{lllllllll}
\hline Grup & Değişken & $\mathbf{p 5 0}$ & İqr & Min & $\mathbf{m a x}$ & $\mathbf{p 2 5}$ & $\mathbf{p 7 5}$ & $\mathbf{N}$ \\
\hline Grup 1 & STAI-S & 3 & 1 & 1 & 5 & 2,5 & 3,5 & 20 \\
Grup 2 & STAI-S & 4 & 1 & 2 & 5 & 3 & 4 & 20 \\
\hline
\end{tabular}

(Grup 1: aynı gün işlem yapılan grup, Grup 2: randevu verilerek işlem yapilan grup)

Çalışmaya katılan gönüllülerin STAI-S değerleri ve seviyeleri cinsiyet açısından karşılaştırıldığında kadın ve erkekler arasında hem STAIS-S değerleri $(\mathrm{p}=0,0026)$, hem de STAI-S seviyeleri $(p=0,0039)$ arasında istatistiksel olarak anlamlı farklılık bulunmuştur (Tablo2, Tablo 3).

Tablo 2. STAI-S seviyesi ortanca değerlerinin cinsiyete göre karşılaştırılması

\begin{tabular}{lllllllll}
\hline Cinsiyet & Değişken & p50 & İqr & Min & max & p25 & p75 & N \\
\hline Erkek & STAI-S & 3 & 1 & 1 & 5 & 2,5 & 3,5 & 18 \\
Kadın & STAI-S & 4 & 1 & 2 & 5 & 3 & 4 & 22 \\
\hline
\end{tabular}

Tablo 3. STAI-S ortanca değerlerinin cinsiyete göre karşılaştırılması

\begin{tabular}{lllllllll}
\hline Cinsiyet & Değişken & p50 & İqr & Min & max & p25 & p75 & N \\
\hline Kadın & STAI-S & 43 & 11 & 25 & 53 & 35 & 46 & 22 \\
Erkek & STAI-S & 34,5 & 6 & 20 & 44 & 31 & 37 & 18 \\
\hline
\end{tabular}

\section{Dental Korku Skalası (DFS) Sonuçları}

Gruplara göre DFS değerleri arasında istatistiksel olarak anlamlı fark olup olmadığına Mann Whitney U testi ile bakılmıştır. Gruplar arasında anlamlı bir farklılık bulunmamıştır ( $\mathrm{p}=0.1802)$.

DFS değerleri hafif, orta ve şiddetli olarak 3 gruba ayrılarak sonuçlar karşılaştırılmıştır ve gruplar arasında istatistiksel olarak anlamlı bir farklılık bulunmamıștır $(\mathrm{p}=0,358)$.

Çalışmaya katılan gönüllülerin DFS değerleri cinsiyet açısından karşılaştırıldığında kadın ve erkekler arasında istatistiksel olarak anlamlı farkl1l1k bulunmuştur $(\mathrm{p}=0,0025)$ (Tablo 4).

Tablo 4. DFS değerlerinin cinsiyete göre dağılımı

\begin{tabular}{lllllllll}
\hline Cinsiyet & Değişken & p50 & İqr & Min & max & p25 & p75 & N \\
\hline Kadın & DFS & 40,5 & 18 & 24 & 60 & 32 & 50 & 22 \\
Erkek & DFS & 28,5 & 10 & 21 & 56 & 24 & 34 & 18 \\
\hline
\end{tabular}

\section{Visual Analog Skala (VAS) Sonuçları}

Çalışmaya katılan gönüllülerin VAS değerlerinin zamanla olan değişimlerinin karşılaştııılmasına Friedman testi ile 
bakılmıştır. VASişlem süresince (VAS 1) - VASişlemden 1 gün sonra (VAS 2) ve VASişlemden 1 hafta sonra (VAS 3) değerleri arasında istatistiksel olarak anlamlı olarak farklılık tespit edilmiştir $(\mathrm{p}=0,0003)$. Farklılığa neden olan grubun tespitinde Wilcoxon testi kullanılmıştır. VAS 2 değerleri anlamlı olarak VAS1 ve VAS3 değerlerinden daha yüksek bulunmuştur (Tablo 5).

Tablo 5. VAS değerlerinin değişimi

\begin{tabular}{lllllll}
\hline Değişken & $\mathbf{p 5 0}$ & İqr & Min & Max & p25 & p75 \\
\hline VAS1 & 1 & 4 & 0 & 7 & 0 & 4 \\
VAS2 & 3 & 4,5 & 0 & 8 & 5 & 5 \\
VAS3 & 1 & 1 & 0 & 3 & 0 & 1 \\
\hline
\end{tabular}

Grupların işlem süresince hissettikleri ağrıya göre yaptıkları VAS skorlaması sonuçları (VAS1) arasında anlamlı bir farklılık olup olmadığına Mann - Whitney testi ile bakılmıştır. Grup 1 VAS değerlerinin, Grup 2 VAS değerlerine göre anlamlı olarak daha düşük olduğu bulunmuştur ( $\mathrm{p}=0,0396)$ (Tablo 6).

Tablo 6. Grupların VAS değerlerinin karşılaştırılması

\begin{tabular}{llllllll}
\hline & Değişken & $\mathrm{p} 50$ & $\mathrm{p} 25$ & $\mathrm{p} 75$ & $\mathrm{Iqr}$ & $\min$ & $\max$ \\
\hline \multirow{3}{*}{ Grup 1 } & VAS1 & 1 & 0 & 2,5 & 2,5 & 0 & 5 \\
& VAS2 & 2,5 & 5 & 5 & 4,5 & 0 & 6 \\
& VAS3 & 1 & 0 & 1 & 1 & 0 & 2 \\
\hline \multirow{3}{*}{ Grup 2 } & VAS1 & 2 & 1 & 5 & 4 & 0 & 7 \\
& VAS2 & 3 & 5 & 5 & 4,5 & 0 & 8 \\
& VAS3 & 1 & 0 & 1,5 & 1,5 & 0 & 3 \\
\hline
\end{tabular}

(Grup 1: aynı gün işlem yapılan grup, Grup 2: randevu verilerek işlem yapilan grup)

Grupların işlemden bir gün sonra (VAS2) ve işlemden 1 hafta sonra (VAS3) hissettikleri ağrıya göre yaptıkları VAS skorlaması sonuçları arasında ise anlamlı bir farklılık bulunmamıştır $(\mathrm{p}=0,9126)(\mathrm{p}=0,1925)$.

\section{TARTIŞMA}

Diş hekimliğindeki tüm teknolojik gelişmelere rağmen diş tedavisine ait anksiyete ve tedavi sırasındaki ağrı korkusu devam etmektedir. Oosterink ve ark. dental tedavi korkusunun (\%49.4), hayvan (\%39), yükseklik (\%30.7), firtına (\%21.1) ve uçma korkusu (\%13.2) gibi bilinen birçok korkudan çok daha fazla gözlendiğini bildirmiştir (10).

Dental tedavinin çeşidi dental anksiyeteyi etkileyen önemli bir faktördür. Wong ve Lytle yaptıkları çalışmada diş çekimi ve kanal tedavisi işlemlerinin hastalar tarafından en korkulan tedaviler olduğunu saptamışlardır (11). Udoye ve arkadaşları da yaptıkları çalışmalarında en yüksek anksiyetenin diş çekimi ve kanal tedavisi işlemleri öncesinde görüldüğünü, bunları dolgu işleminin takip ettiğini bildirmiştir (12). Diş çekimi işlemine bağlı oluşan korkunun temelinde, vücut bütünlüğünün bozulması, bir organ kaybediyor olma fikri yer almaktadır. Ayrıca diş çekimi öncesi yapılan enjeksiyon işlemi de literatürde en çok anksiyete yaratan durumlardan biri olarak rapor edilmektedir $(4,13)$. Diş çekimine bağlı oluşan anksiyete ve korkuyu etkileyen faktörlerin belirlenmesine yönelik pek çok çalışma yapılmıştır (14-21). Fakat literatürde diş çekimi işleminin hemen ya da randevulu yapılmasının dental anksiyete ve korku üzerine etkinliğinin değerlendirildiği çalışmaya rastlanmamıştır. Bu sebeple bu çalışma operasyon zamanlamasının dental anksiyete ve korku üzerine etkisinin değerlendirmek amacıyla yapılmıştır.

Durumluluk Kayg1 Ölçeği (STAI-S) ve Sürekli Kayg1 Ölçeği(STAI-T) olmak üzere iki bölümden oluşan Spielberger Anksiyete Skalası (STAI), dental anksiyetenin ölçülmesi için özel olarak geliştirilmiş bir yöntem değildir fakat literatürde, dental anksiyeteyi ölçmeye yönelik çok sayıda çalışmada kullanılmıştır ve güvenilirliği ispatlanmıştır $(14,17,18,20,21)$. Sürekli Kayg1 Ölçeği, kişinin yaşadığı durum ve koşullardan bağımsız olarak kendini nas1 hissettiğini; genel olarak anksiyete düzeyini belirlemektedir. Durumluluk Kayg1 Ölçeği ise kişinin belirli bir anda ve belirli durumda kendini nasıl hissettiğini, anksiyetesinin derecesini belirlemek amaciyla kullanılır. $\mathrm{Bu}$ tez çalışmasında da her iki tedavi grubundaki gönüllülerin, diş çekimi öncesinde dental anksiyete seviyelerinin belirlenmesi amacıyla Durumluluk Kaygı Ölçeği Skalası kullanılmıştır.

Araştırmalarda sıklıkla kullanılan bir diğer test ise Kleinknecht tarafından geliştirilmiş olan ve dental korkunun farklı boyutlarda incelenmesini sağlayan Dental Korku Skalası' dır. Bu skala, diş hekimine gitmekten kaçınma, korkunun somatik semptomları ve diş hekimliği pratiğindeki çeşitli uygulamalara karşı duyulan korku düzeyini inceleyen bir skaladır (22). BU çalışmada da her iki tedavi grubundaki gönüllülerin, diş çekimi öncesinde dental korku seviyelerinin belirlenmesi amaciyla bu skala kullanılmıştır.

Çalışmaların çok büyük bir kısmında anksiyete ve akut ağrı algısı arasında güçlü bir ilişki olduğu kanıtlanmıştır (23). Arntz ve arkadaşları yüksek seviyede dental anksiyetesi olan 
hastaların işlemden bekledikleri ağrı seviyesinin yüksek olduğunu bildirmişlerdir (3) . Ağrı duyusu veya beklentisi, hastanın duygusal hali ve anksiyete seviyesi ile yakından ilişkilidir; anksiyete ağrı beklentisini artırmakla beraber ağrı beklentisi anksiyete kaynağıdır (24). Subjektif ağrının ölçülmesinde Vizüel Analog Skala (VAS) yaygın olarak kullanılan bir yöntemdir. Oldukça basittir, tekrar edilebilir ve istatistik çalışmaları için uygundur. Bu tez çalışmasında gönüllülerin anksiyete seviyeleri ile hissettikleri ağr1 seviyeleri arasında bir ilişki olup olmadığını görmek amacıyla, diş çekimi süresince, işlemden bir gün sonra ve işlemden 1 hafta sonra hissettikleri ağrıyı VAS skalasına göre puanlamaları istenmiştir. Ağrı 0 rakamının ağrısız, 10 rakamının ise hissedilebilecek en şiddetli ağrıyı gösterdiği tanımlayıcı numerik değerlendirme skalası kullanılarak değerlendirilmiştir.

Oral cerrahi işlem tecrübesi olan hastaların, tecrübesi olmayan hastalara göre daha düşük düzeyde anksiyete gösterdikleri belirtilmektedir. Yusa ve arkadaşları daha önce 20 yaş dişi çekimi yapılan hastaların ikinci çekimde, ilk defa çekim yaptıran hastalara göre daha az anksiyete gösterdiklerini belirtmişlerdir (25).

Ayrıca oral cerrahi işlemlerle ilgili olumsuz bilgi edinen hastaların, bilgisi olmayan hastalara göre daha anksiyetik olduğu gösterilmiştir (11). Bu çalışmada da hastaların daha önce gömülü 20 yaş dişi operasyonu geçirmiş olmaları ve buna bağlı olumlu/ olumsuz tecrübeleri ameliyat öncesi anksiyete değerlerini etkileyeceği için, ameliyat tecrübesi olmayan hastalar çalışmaya dahil edilmiştir.

Dental anksiyeteyi etkileyen faktörlerden biri de cinsiyettir. Yapılan çalışmalarda kadınlarda erkeklere göre anksiyete skorları yüksek bulunmuştur $(2,14,20,21)$. Stouthard ve Hoogstraten yapmış oldukları çalışmada kadınlardaki anksiyete skorlarının daha yüksek bulunmasının sebebinin, erkeklerin korku ve anksiyetelerini kadınlar kadar kolay dışa vuramamalarından kaynaklandığını savunmuşlardır (26). Jongh ve arkadaşları yapmış oldukları çalışmada kadın hastalardaki anksiyete skorlarının erkek hastalardan yüksek olduğunu rapor etmişlerdir ve bunun sebebinin, kadın bireylerin sorulan sorulara daha dürüst cevap vermelerinden kaynaklanabileceğini ifade etmişlerdir (27). Bu tez çalışmasında da kadınların STAI-S ortanca değerleri $(\mathrm{p} 50=43)$, erkeklerin STAI-S ortanca değerlerinden $(\mathrm{p} 50=34,5)$ anlamlı olarak daha yüksektir $(\mathrm{p}=0,0026)$. Aynı zamanda kadınlardaki STAI-S seviyesi ortanca değeri de $(\mathrm{p} 50=4)$ erkeklerden $(\mathrm{p} 50=3)$ anlaml olarak daha yüksektir ( $p=0,0039)$. Gönüllülerin DFS skorları değerlendirildiğinde de kadınların DFS ortanca değerlerinin $(\mathrm{p} 50=40,5)$, erkeklerin DFS ortanca değerlerinden (p50=28,5) anlamlı olarak daha yüksek olduğu görülmüştür.

Eğitim durumu anksiyeteyi etkileyebilen bir diğer önemli faktördür. Bazı araştırmaların sonuçlarına göre dental anksiyete, düşük sosyal sinıflarda, eğitim ve gelir düzeyi düşük olan gruplarda daha yaygındır $(2,28)$. Ragnarsson, yüksek eğitim seviyesine sahip hastaların daha düşük anksiyete skorları gösterdiğini bildirmiştir (29).

Bunun aksini belirten çalışmalar da mevcuttur. Egbor ve Akpata eğitim seviyesi düşük bireylerde daha düşük anksiyete değerlerinin tespit edildiğini bildirmişlerdir (30). Hastaların eğitim durumlarıyla anksiyete seviyeleri arasında herhangi bir ilişki bulunmadığını bildiren çalışmalar da mevcuttur $(14,15,20)$. Bu tez çalışmasına katılan gönüllülerin $\% 12,5$ 'i ilköğretim, $\% 52,5$ 'i ortaöğretim, $\% 35$ 'i ise yükseköğretim mezunudur. Bu üç eğitim seviyesi ile STAI-S ve DFS skorları arasında istatistiksel olarak anlamlı bir ilişki tespit edilmemiştir $(\mathrm{p}=0,4935)(\mathrm{p}=0,8527)$.

Çalışma grupları karşılaştırıldığında ise fakülteye başvurduğu gün yirmi yaş cerrahisi yapılan gönüllülerin (Grup1) STAI-S seviyesi, randevu verilerek işlem yapılan gönüllülerin (Grup 2) STAI-S seviyesine göre anlaml olarak daha düşüktür $(\mathrm{p}=0,0269)$.

DFS sonuçları karşılaştırıldığında ise Grup 1 ve Grup 2 arasında anlamlı bir farklılık bulunmadığ 1 görülmüştür $(\mathrm{p}=0,1802)$.

Anksiyete duyarlılığı artmış ve dental korkusu olan kişilerde işlem sırasında algılanan ağrı miktarını abartma eğilimi çok daha yüksek olarak bulunmuştur (31-33). Yüksek düzeyde anksiyete gösteren hastaların işlemden bekledikleri ağrı seviyesinin de yüksek olduğu bildirilmiştir $(3,14)$.

Scottt ve arkadaşları artmış preoperatif anksiyetenin artmış post-operatif ağrıyla ilişkisi olduğunu ifade etmişlerdir (34).

Vallerand ve arkadaşları endişeli hastaların dental işlemler sırasında ve post operatif dönemde daha şiddetli ve uzun süreli ağrı hissettiklerini bildirmiştir (35). Bu tez çalışmasında da ağrı seviyesi ile dental anksiyete arasında bir ilişki olup olmadığı sorusuna cevap aranmıştır. Gönüllülerin ağrı seviyeleri üç farklı zamanda (VAS1: işlem süresince, VAS2: işlemden 1 gün sonra, VAS3: işlemden 1 hafta sonra) değerlendirilmiştir. 
VAS1 değerleri incelendiğinde, Grup1' deki gönüllülerin Grup 2' deki gönüllülere göre anlamlı olarak daha düşük VAS değerlerine sahip olduğu görülmüştür $(\mathrm{p}=0,0396)$. Gruplar karşılaştırıldığında, STAI-S skorları ve VAS1 değerleri arasında paralellik olduğu tespit edilmiştir. Dental anksiyete skoru düşük olan gönüllülerin yirmi yaş cerrahisi boyunca hissettikleri ağrı derecesi de anlamlı olarak daha düşüktür.

VAS2 ve VAS3 değerleri incelendiğinde, Grup 1 ve Grup 2 arasındaki anlamlı farkın kaybolduğu görülmüştür. Fakat VAS1 ile karşılaştırıldığında her iki tedavi grubunda da VAS2 değerlerinin anlamlı olarak daha yüksek olduğu görülmüştür. İşlemden 1 gün sonra ağrı seviyesinin yükselmesi, yirmi yaş dişi cerrahisi sonrası görülebilen bir komplikasyon olarak düşünülmüştür.

\section{SONUÇLAR}

Çalışmaya katılan kadın gönüllülerin STAI-S skorları erkeklere göre daha yüksektir. Eğitim seviyesi ile dental anksiyete değerleri arasında anlamlı bir ilişki bulunmamıştır. Fakülteye başvurduğu gün gömülü yirmi yaş dişi cerrahisi yapılan gönüllülerin dental anksiyete seviyeleri ve işlem süresince hissettikleri ağrı seviyeleri randevu verilerek işlem yapılan gönüllülere göre anlamlı olarak daha düşük bulunmuştur. Gömülü yirmi yaş dişi cerrahisi için randevu verilmesi hastaların anksiyete ve ağrı seviyelerini yükseltebildiğinden, operasyonların hemen yapılması hastaların yararına olacaktır.

\section{KAYNAKLAR}

1. Zafersoy Akarslan Z, Erten H. Diş Hekimliği Korkusu ve Kaygis1. CDR. 2009;1:62-8.

2. Armfield JM, Spencer AJ, Stewart, JF. Dental fear in Australia: who's afraid of the dentist? Aust Dent J. 2006; 51:(1)78-85.

3. Arntz A, van Eck M, Heijmans M. Predictions of dental pain: the fear of any expected evil, is worse than the evil itself. Behav Res Ther. 1990; 28:29-41.

4. Berggren U, Meynert G. Dental fear and avoidance: causes, symptoms, and consequences. J Am Dent Assoc.1994;109: (2) 247-251.

5. Neverlien PO, Backer JT. Optimism-pessimism dimension and dental anxiety in children aged 10-12 years. Community Dent Oral Epidemiol. 1991;19(6):342-6. .

6. Weiner AA, Sheehan DV. Etiology of dental anxiety: psychological trauma or CNS chemical imbalance? Gen Dent. 1990; 38(1):39-43.
7. Akarslan ZZ, Yıldırım Biçer AZ. Influence of gag reflex on dental attendance, dental anxiety, self-reported temporomandibular disorders and prosthetic restorations. J Oral Rehabil. 2013; 40(12):932-9.

8. Erten H, Akarslan ZZ, Bodrumlu E. Dental fear and anxiety levels of patients attending a dental clinic. Quintessence Int. 2006; 37(4):304-10.

9. Quteish Taani DS. Dental fear among a young adult Saudian population. Int Dent J. 2001; 51(2):62-6.

10. Oosterink, FM., de Jongh, A, Hoogstraten J. Prevalence of dental fear and phobia relative to other fear and phobia subtypes. 2009; Eur J Oral Sci 117:135-143.

11. Wong M, Lytle WR. A comparison of anxiety levels associated with root canal therapy and oral surgery treatment. J Endod. 1991; 17:461-465.

12. Udoye CI, Oginni AO, and Oginni FO. Dental anxiety among patients undergoing various dental treatments in a Nigerian teaching hospital. 2005; J Contemp Dent Pract 6:91-98.

13. Moore R, Birn H, Kirkegaard E, Brodsgaard I, Scheutz F. Prevalence and characteristics of dental anxiety in Danish adults. Community Dent Oral Epidemiol. 1993; 21: (5) 292296.

14. Muglali M, Komerik N. Factors related to patients' anxiety before and after oralsurgery. J Oral Maxillofac Surg 2008;66:870-7.

15. Kim YK, Kim SM, Myoung H. Independent predictors of satisfaction in impacted third molarsurgery patients. Community Dent Oral Epidemiol 2010;38:274-86.

16. McNeil DW, Helfer AJ, Weaver BD, Graves RW, Kyle BN, Davis AM. Memory of pain and anxiety associated with tooth extraction. J Dent Res 2011;90:220-4.

17. Seto M, Sakamoto Y, Takahashi H, Kita R, Kikuta T. Does planned intravenous sedation affect preoperative anxiety in patients? Int J Oral Maxillofac Surg 2012; 42:497-501.

18. Abdeshahi SK, Hashemipour MA, Mesgarzadeh V, Shahidi Payam A, Halaj Monfared A. Effect of hypnosis on induction of local anaesthesia, pain perception, control of haemorrhage and anxiety during extraction of third molars: a case-control study. JCraniomaxillofac Surg 2013;41:310-5.

19. Glaesmer H, Geupel H, Haak R. A controlled trial on the effect of hypnosis on dental anxiety in tooth removal patients. Patient Educ Couns 2015;98:1112-5.

20. Kazancioglu HO, Tek M, Ezirganli S, Demirtas N. Does watching a video on third molar surgery increase patients' anxiety level? Oral Surg Oral Med Oral Pathol Oral Radiol 2015;119:272-7.

21. Tarazona B, Tarazona-Alvarez P, Penarrocha-Oltra D, RojoMoreno J, PenarrochaDiago M. Anxiety before extraction of impacted lower third molars. Med Oral Patol Oral Cir Bucal 2015;20:246-50.

22. Kleinknecht RA, Klepac RK, Alexander LD. Origins and characteristics of fear of dentistry. J Am Dent Assoc. 1973; 86 (4), 842-848.

23. Williams DA. In: Gatchel RJ, Turk DC, editors. Psychosocial factors in pain. New York: Guilford; 1999;p: 151-163.

24. Muğlalı M. Ağız cerrahisi ve anksiyete. Cumhuriyet Üniv Diş Hek Fak Derg.2005; 8:83-88. 
25. Yusa H, Onizawa K, Hori M, Takeda S, Takeda H, Fukushima $\mathrm{S}$, Yoshida H. Anxiety measurements in university students undergoing third molar extraction. Oral Surg Oral Med Oral Pathol Oral Radiol Endod. 2004;98:23-27.

26. Stouthard ME, de Jongh A, Hoogstraten J. Dental anxiety: the use of photographs. Ned Tijdschr Tandheelkd. 1991; 98(4):152-5.

27. Jongh A, Ollf M, Hoolwerff H, Irene HA. Anxiety and posttraumatic stress symptoms following wisdom tooth removal. Behav Res and Ther. 2008; 46: 1305-10.

28. Lopez - Journet P, Camacho-Alonso F, Sanchez - Siles M. Assessment of general pre and postoperative anxiety in patients undergoing tooth extraction: a prospective study. $\mathrm{Br}$ J Oral and Maxillofac Surg. 2014; 52: 18-23.

29. Ragnarsson E. Dental fear and anxiety in an adult Icelandic population. Acta Odontol Scand. 1998; 56(2): 100-104.
30. Egbor PE, Akpata O. An evaluation of the sociodemographic determinants of dental anxiety in patients scheduled for intraalveolar extraction. Libyan J Med. 2014;9:25-43.

31. Keogh E, Mansoor L. Investigating the effects of anxiety sensitivity and coping on the perception of cold pressor pain in healthy women. Eur J Pain. 2001;5:11-22.

32. Keogh E,Chaloner N. The moderating effect of anxiety sensitivity on caffeine-induced hypoalgesia in healthy women. Psychopharmacology. 2002;164:429-431.

33. Schmidt NB, Cook JH. Effects of anxiety sensitivity on anxiety and pain during a cold pressor challenge in patients with panic disorder. Behav Res Ther.1999; 37:313-323.

34. Scott LE, Clum GA, Peoples JB. Preoperative predictors of postoperative pain. Pain.1993;15(3): 283-293.

35. Vallerand WP, Vallerand AH, Heft $M$. The effects of postoperative preparatory information on the clinical course following third molar extraction. J Oral Maxillofac Surg. 1994;52(11): 1165-1170. 